\title{
Performance Analysis of Tropospheric Radio Refractivity on Radio Field Strength and Radio Horizon Distance and Its Variation with Meteorological Parameters over Osogbo, Nigeria
}

\author{
D. O. Akpootu ${ }^{1}$, R. S. Said ${ }^{2}$, W. Mustapha ${ }^{3}$, S. P. Arewa ${ }^{4}$, H. T. Sulu ${ }^{5}$, M. I. Iliyasu ${ }^{5}$ and \\ S. I. Salifu ${ }^{6}$ \\ ${ }^{1}$ Department of Physics, Usmanu Danfodiyo University, Sokoto, Nigeria \\ ${ }^{2}$ Department of Physics, Bayero University, Kano, Nigeria \\ ${ }^{3}$ Nigerian Meteorological Agency (NIMET), Abuja, Nigeria \\ ${ }^{4}$ Research Scholar, Department of Physics, Usmanu Danfodiyo University, Sokoto, Nigeria \\ ${ }^{5}$ Physics Unit, Umaru Ali Shinkafi Polytechnic, Sokoto State, Nigeria \\ ${ }^{6}$ Department of Physics, Kogi State College of Education Technical Kabba, Nigeria
}

\begin{abstract}
Radio refractivity estimation is paramount in the planning and design of radio link/systems for the purpose of achieving optimal performances. In this study, the monthly average daily atmospheric pressure, relative humidity and temperature data obtained from the National Aeronautics and Space Administration (NASA) during the period of twenty two years (July 1983 - June 2005) for Osogbo (Latitude $7.47^{\circ} \mathrm{N}$, Longitude $4.29^{\circ} \mathrm{E}$, and $302.0 \mathrm{~m}$ above sea level) were used to estimate the monthly tropospheric radio refractivity and to investigate its variation with other meteorological parameters of monthly average daily atmospheric pressure, relative humidity, absolute temperature, saturation vapour pressure and radio refractive index. The field strength variability (FSV) and the radio horizon distance were also computed. The monthly variation of FSV using two years data (20032004) was also investigated. The results of this study revealed that the values of radio refractivity are more during the rainy season than in the dry season. It was found that the maximum average value of tropospheric radio refractivity of $370.98 \mathrm{~N}$-units and minimum average value of $332.36 \mathrm{~N}$-units occurred in the months of May and January during the rainy and dry seasons respectively. $71.45 \%$ of the total value of the radio refractivity was contributed by the dry term while the major variation is by the wet term radio refractivity. The average refractivity gradient computed for the study area under investigation was $-42.69 \mathrm{~N}$ units/km and the average effective earth radius ( $k$-factor) was 1.37 which corresponds to the conditions of super refraction. The annual maximum mean value of FSV is $7.72 \mathrm{~dB}$ and minimum monthly mean value of $0.07 \mathrm{~dB}$ was obtained for the study area. The implication of this FSV values is that the output of a receiving antenna in Osogbo may generally be subjected to changes not less than $0.07 \mathrm{~dB}$ in a year and not greater than $7.72 \mathrm{~dB}$. The descriptive statistical analysis shows that the radio refractivity, relative humidity, absolute temperature and radio refractive index data spread out more to the left of their mean value (negatively skewed), while the atmospheric pressure data spread out more to the right of their mean value (positively skewed). The radio refractivity, relative humidity and radio refractive index data have positive kurtosis which indicates a relatively peaked distribution and possibility of a leptokurtic distribution. The atmospheric pressure and absolute temperature data have negative kurtosis which indicates a relatively flat distribution and possibility of platykurtic distribution.
\end{abstract}

Keywords: Radio refractivity, field strength variability (FSV), radio horizon distance, refractivity gradient, effective earth radius, descriptive statistics.

\section{INTRODUCTION}

The process of transmitting information or ideas through the exchange of thoughts, speech, messages, signals, visuals, writing, or behavior is called Communication. It is the meaningful exchange of information between a source and a receiver. Basically, a message is sent from the source through a medium to the receiver [1]. Radio wave propagation is the sending out of electromagnetic energy from a transmitter to a receiver and it is affected by the rate of change of the radio refractivity with 
altitude in the troposphere [2 - 3].Mobile communication systems employ the microwave frequency bands because of its broad bandwidth [4]. However, electromagnetic waves (EMW) energy in this band can be reflected, refracted, scattered, and absorbed by different atmospheric constituents. Electromagnetic waves (EMW) propagation through the atmosphere is affected by the atmosphere itself [5]. In general, environmental effects on communication systems are divided into three categories: attenuation, or loss of energy of the radiation beam because of beam interaction with absorbing or scattering constituents in the beam path; refraction, or bending of the beam due to atmospheric density variations along the beam path; and scintillation or distortion of the beam due to small scale atmospheric turbulence [6].

The part of the atmosphere most closely related to human life is the troposphere [7]. It is the lowest layer of earth's atmosphere and region of all weather on earth [7]. The troposphere extends from the earth's surface to an altitude of about $10 \mathrm{~km}$ at the earth's poles and $17 \mathrm{~km}$ at the equator and tends to affect radio frequencies above $30 \mathrm{MHz}$ [8]. However, the second layers that is of interest from a radio communications perspective apart from the troposphere is the ionosphere which is a region that extends from around $60 \mathrm{~km}$ up to $700 \mathrm{~km}$ producing ions and free electrons which affect radio signals at certain frequencies; typically those below $30 \mathrm{MHz}$ [9]. Since temperature decreases with altitude in the troposphere [10], warm air near the surface of the earth can rapidly rise replacing the cold dense air at the upper part of the atmosphere. This will set up convection current in the air molecules of the troposphere. Such vertical movement or convection current creates clouds and ultimately rain from the moisture within the air, and gives rise to the weather condition we experience. At the lower part of the earth called the troposphere, the tropospheric refraction is due to the fluctuations of weather parameters like temperature, pressure and relative humidity [11].

Knowledge of the refractivity is thus essential in order to design reliable and efficient radio communication (terrestrial and satellite) systems. Similarly, to estimate the performance of terrestrial radio links, the refractive index of the troposphere is equally a very important parameter to be considered [9]. The atmosphere radio refractive index depends on air temperature, humidity, atmospheric pressure and water vapour pressure. Even small changes in any of these variables can make a significant influence on radio-wave propagation, because radio signals can be refracted over the whole signal path [12]. Refractive index is not constant in the atmosphere and its space-time distribution results in scattering, sub-refraction, super-refraction, ducting and absorption phenomena [13]. The variation of refractive index as well as specific attenuation of micro/radio wave may be estimated indirectly with the measurement of temperature, pressure and relative humidity [7].

In radio frequency telecommunications, field strength is the magnitude of the received electromagnetic field which will excite a receiving antenna and thereby induce a voltage at a specific frequency in order to provide an input signal to a radio receiver [1]. How far a radio signal will travel within the radio horizon is determined by the distribution of the radio refractivity [1]. Several researchers like [1], [7] and [14 - 19] have carried out studies on radio refractivity for different regions and climates using measured local meteorological data in Nigeria and other parts of the world. The results of their study showed that the local climate has a substantial influence on the radio refractivity and consequently on the transmitted radio signals. Similarly, researchers like [1], [6] and [20] have studied electromagnetic wave (EMW) medium interaction processes and the propagation implications over Nigeria, especially the study of variation of radio field strength and radio horizon distance over few stations in Nigeria. As a result of the variation of meteorological parameters in each geographical location; it is inadequate to generalize the variation of radio field strength and radio horizon distance over Nigeria.

The purpose of this study is to (i) estimate the tropospheric radio refractivity and investigate its variation with meteorological parameters of atmospheric pressure, relative humidity and temperature for Osogbo, Osun state, Nigeria using meteorological data obtained from the National Aeronautics and Space Administration (NASA) during a period of twenty two years (July 1983 - June 2005) (ii) investigate field strength variability for the location (iii) establish an expression for estimating radio horizon distance for the location (iv) carry out descriptive statistical analysis to ascertain the behavior of the skewness and kurtosis for the location.

\section{STUDY AREA}

Osogbo, is a city in Nigeria and the capital of Osun State, is located on latitude $7.47^{\circ} \mathrm{N}$ and longitude $4.29^{\circ} \mathrm{E}$ in Southwest of Nigeria (Figure 1). It has a population density of 350-500 persons $/ \mathrm{m}^{2}$ [21]. The population of Osogbo grew from 106,386 to 155 , 507 between 1991- 2006 [22]. Osogbo city seats the Headquarters of both Osogbo Local Government Area (situated at Oke Baale Area of the city) and Olorunda Local Government Area (situated at Igbonna Area of the city). The city is bounded by Kwara State to the north, Ogun State to the south, Ekiti and Ondo State to the east and Oyo State to the west. The state is within the tropical rain forest with abundance of resources. Minerals resources found in the state include gold, kaolin and others which are being extracted for the benefit of the state and the people. It is some 88 kilometers by road northeast of Ibadan (capital of Oyo state). It is 115 kilometers by road northwest of Akure (capital of Ondo state) and 100 kilometers south of Ilorin (capital of Kwara state); because of its central nature, Osogbo is easily accessible from Ikirun, Ilesha, Ede, Egbedore and Iragbiji where it shares boundary 
with. It is about $48 \mathrm{~km}$ from Ife, $32 \mathrm{~km}$ from Ilesa, $46 \mathrm{~km}$ from Iwo, $48 \mathrm{~km}$ from Ikire and $46 \mathrm{~km}$ from Ila-Orangun; The state also has many hills in towns like Ikirun, Iragbiji, Ilesha, Ikire and Ile-Ife. These hills were fortresses for the people during the Yoruba wars and the Fulani expansionist period. Presently, they serve as beautiful sceneries and landscape to look upon when visiting or passing through these towns. Osogbo is the trade center for a farming region. Yams, cassava, grain, and tobacco are grown. Cotton is grown and used to weave cloth.

Osogbo experiences a warm humid tropical climate, with two distinct seasons, the rainy and dry seasons. The rainy season lasts for about seven months, April to October while the dry season lasts from November to March. In Osogbo, the rainy season is warm, oppressive, and overcast and the dry season is hot, muggy, and partly cloudy. The temperature typically changes from $65^{\circ} \mathrm{F}$ to $93^{\circ} \mathrm{F}$ and is rarely fall below $60^{\circ}$ For above $98^{\circ} \mathrm{F}$. Based on the beach/pool score, the best time of year to visit Osogbo for hotweather activities is from late November to early February. Osogbo is characterized by Guinea Savannah climate with annual rainfall range of $1100-1500 \mathrm{~mm}$. It has an average daily temperature of $26{ }^{\circ} \mathrm{C}$, average annual relative humidity of $83 \%$. However, the relative humidity can be up to $90 \%$ during the rainy season.

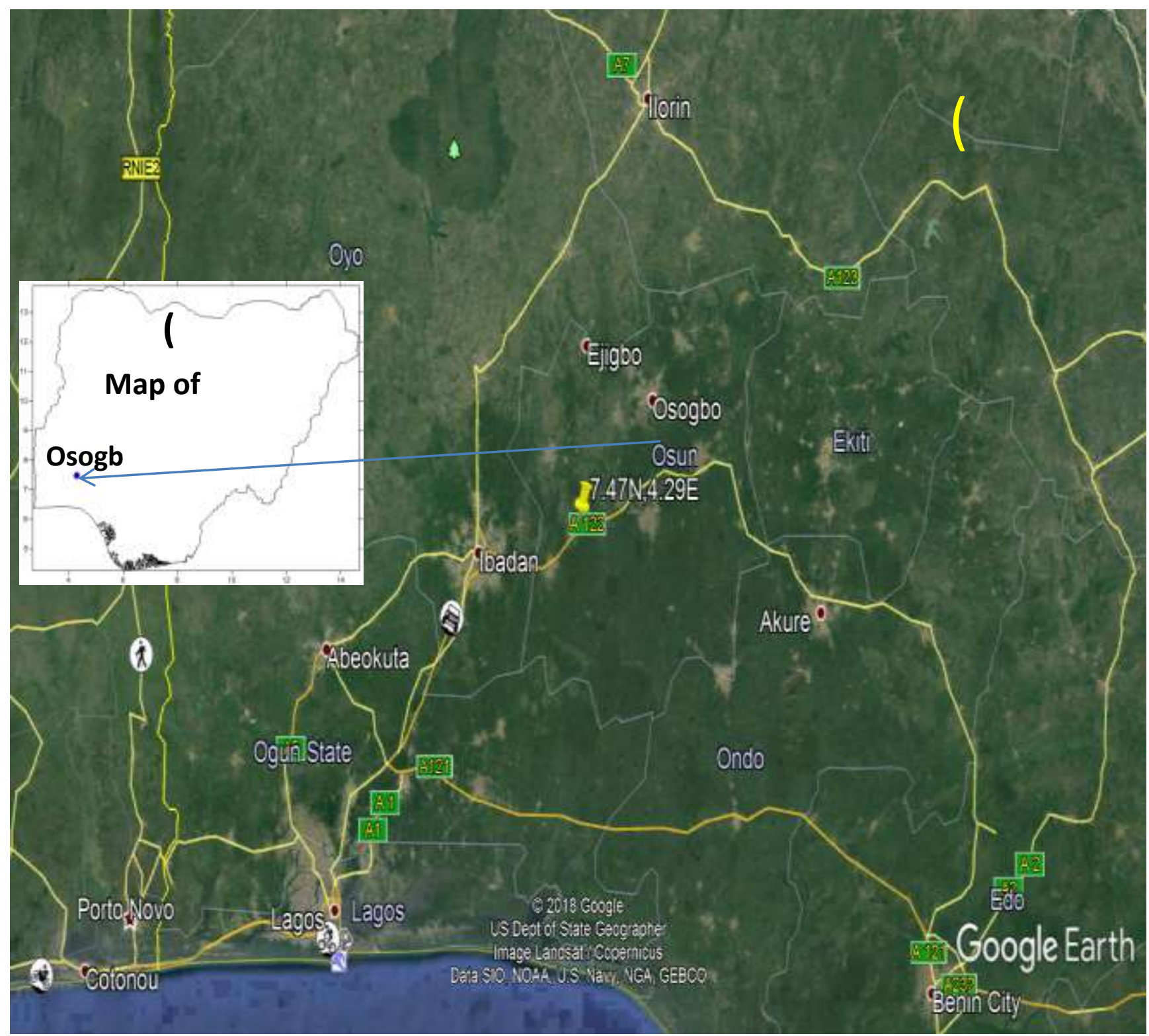

Figure 1. Map of (a) Google map showing the study area (b) Map of Nigeria showing the study area

\section{METHODOLOGY}

The measured daily climatic data of atmospheric pressure, relative humidity and temperature utilized in this present work were obtained from the National Aeronautics and Space Administration (NASA) atmospheric science data centre under Surface meteorology and Solar Energy. The daily averaged data were averaged into monthly averaged data. The study area under 
investigation is Osogbo (Latitude $7.47^{0} \mathrm{~N}$, Longitude $4.29^{0} \mathrm{E}$ and altitude $302.0 \mathrm{~m}$ above sea level). To avoid possible misleading indications related to year to year variation in weather condition, the period under focus is twenty two years (July 1983 - June 2005) so as to obtain a good climatological average. The quality assurance of the meteorological measurements was determined by checking the overall consistency of the monthly average of the climatic parameters used in the study area.

The refractive index, $n$ of the atmosphere is dependent upon three factors, these are, atmospheric pressure, temperature and humidity (water vapour content). The values of the refractive index, $n$, varies between 1.000250 and 1.000400 indicating that it is very close to unity at or near the earth's surface and variation in this value is very small in time and in space. With the aim of making them more noticeable, the refractive index, $n$ of air is measured by a quantity called the radio refractivity, $N$ which is related to the refractive index, $n$ as [3]; [23].

$$
n=1+N \times 10^{-6}
$$

Although, the radio refractivity, $N$, is a dimensionless quantity, it is expressed in N-units. Therefore from equation (1) it is easy to deduce that a typical range of $N$ will be between 250 and $400 \mathrm{~N}$-units. In terms of meteorological parameters, the International Telecommunication Union (ITU) has recommended the radio refractivity, $N$, to be expressed as [23].

$$
N=\frac{77.6}{T}\left(P+4810 \frac{e}{T}\right)=N_{d r y}+N_{w e t}
$$

with the "dry term" of radio refractivity given by:

$$
N_{d r y}=77.6 \frac{P}{T}
$$

and the "wet term" of radio refractivity given by:

$$
N_{\text {wet }}=3.73 \times 10^{5} \frac{e}{T^{2}}
$$

where $P$ is the atmospheric pressure $(h P a), T$ is the absolute temperature $(K)$ and $e$ is the water vapour pressure $(h P a)$. The dry term is due to non-polar nitrogen and oxygen molecules. It is proportional to pressure, $\mathrm{P}$, and therefore, related to the air density. The wet term is proportional to vapor pressure and dominated by polar water contents in the troposphere.

It was mentioned in Freeman [3] and ITU-R [23] that the expression (2) may be used for all radio frequencies; for frequencies up to $100 \mathrm{GHz}$, the error is less than $0.5 \%$. At sea level, the average value of $N \approx 315$ [23] is used.

The relationship between water vapour pressure, $e$, and relative humidity is given by the expression as [23]:

$$
e=\frac{H e_{s}}{100}
$$

where

$$
e_{s}=a \exp \left(\frac{b t}{t+c}\right)
$$

where $H$ is the relative humidity $(\%), t$ is the Celsius temperature $\left({ }^{\circ} \mathrm{C}\right)$ and $e_{S}$ is the saturation vapour pressure $(h P a)$ at temperature $\left({ }^{\circ} \mathrm{C}\right)$. The values of the coefficients $a, b$ and $c$ (for water and ice) are presented in ITU-R [23]. In this study, that for water are adopted and are given as $a=6.1121 b=17.502$ and $c=240.97$ and are valid between $-20^{\circ}$ to $+50^{\circ}$ with an accuracy of $\pm 0.20 \%$. The radio refractivity, $N$, also decrease exponentially in the troposphere with height [23].

$$
N=N_{s} \exp \left(\frac{-h}{H}\right)
$$

where $N$ is the refractivity at the height $h(\mathrm{~km})$ above the level where the refractivity is $N_{s}$ while $H$ is the applicable scale height. ITU-R [23] suggested that at average mid-latitude, $N_{s}$ and $H$ are 315 and $7.35 \mathrm{~km}$ respectively. Hence, $N$ as a function of height $N(h)$ and is given by the expression

$$
N=315 \exp ^{-0.136 h}
$$

However, the results of the work of Agunlejika and Raji [24] showed that the model using the scale height of $7.35 \mathrm{~km}$ and $7 \mathrm{~km}$ as recommended for global environment [23] and tropical environment [10] respectively gave reasonably accurate results for the refractivity at the altitude of $50 \mathrm{~m}$ and $200 \mathrm{~m}$ for seven out of the twelve months of the year. Although the scale height of $7 \mathrm{~km}$ gave a better result at $50 \mathrm{~m}$ altitude while $7.35 \mathrm{~km}$ scale height gave a better performance at $200 \mathrm{~m}$.

The refractivity gradient is obtained by differentiating equation (7) with respect to $h$, therefore, we've the refractivity gradient as 


$$
\frac{d N}{d h}=\frac{-N_{S}}{H} \exp \left(\frac{-h}{H}\right)
$$

For a standard atmosphere, the refractivity gradient is $-39 \mathrm{~N}$-units $/ \mathrm{km}$. According to John [10], when $h<1 \mathrm{~km}$, refractivity gradient is well approximated by its value in a standard atmosphere. In this study we used the typical values for a standard atmosphere [10], and obtained the refractivity of a standard atmosphere as $N_{S}=312 \mathrm{~N}-$ units.

In the troposphere, the vertical gradient of refractivity is an important parameter in estimating path clearance and propagation effects such as sub-refraction, super refraction, or ducting in accordance with the following conditions [2]:

- Sub-refraction: $\frac{d N}{d h}>-40$

The tropospheric radio refractivity increases with height and in this condition (sub-refraction), the radio wave moves away from the earth's surface and the line of sight range and the range of propagation decrease consequently.

- Super-refraction: $\frac{d N}{d h}<-40$

For super-refractive to take place, the electromagnetic waves (EMW) are bent downward towards the earth. The extent at which it bends depends basically on the strength of the super-refractive condition. The radius of curvature of the ray path is smaller than the earth's radius and the rays leaving the transmitting aerial at small angles of elevation will go through total internal reflection in the troposphere and then return to the earth at some distance from the transmitter. On reaching the earth's surface and being reflected from it, the waves can skip large distances, thereby producing abnormally large ranges beyond the line of sight as a result of multiple reflections.

- Ducting: $\frac{d N}{d h}<-157$

When the electromagnetic waves bend downwards with a curvature greater than that of the earth, ducting is said to take place. Radio energy bent downwards may be trapped between a boundary or layer in the troposphere and the surface of the earth or sea (surface duct) or between two boundaries in the troposphere (elevated duct). In this wave guide-like propagation, very high signal strengths can be attained at very long range (far beyond line-of-sight) and the signal strength may surpass its free-space value.

The effective earth radius factor $k$ can be used to characterise refractive conditions as normal refraction or standard atmosphere, sub-refraction, super-refraction and ducting respectively. Thus, $k$ may be expressed in terms of refractivity gradient, $d N / d h$ as [3], [25-27].

$$
k \approx\left[1+\frac{\left(\frac{d N}{d h}\right)}{157}\right]^{-1}
$$

Near the earth's surface, $\frac{d N}{d h}$ is about $-39 \mathrm{~N}$-units $/ \mathrm{km}$ which gives an effective earth radius factor, $=\frac{4}{3}$. This is referred to as normal refraction or standard atmosphere. Here, radio signals travel on a straight line path along the earth's surface and go out to space unobstructed.

If $\frac{4}{3}>k>0$ Sub-refraction occurs, meaning that radio waves propagate abnormally away from the earth's surface.

When $\infty>k>\frac{4}{3}$ In this case, Super-refraction occurs and radio waves propagate abnormally towards the earth's surface thus extending the radio horizon. Lastly,

If $-\infty<k<0$ ducting occurs and the waves bend downwards with a curvature greater than that of the earth.

Surface refractivity correlates highly with radio field strength especially at Very High Frequencies (VHF). In the frequency range 30-300 MHz, a factor of $0.2 \mathrm{~dB}$ change in field strength may be adopted for every unit change in $N_{s}$ [28 - 29].Using the surface refractivity, $N_{S}$ values obtained using equation (2), the maximum $\left(N_{S(M A X)}\right)$ and minimum $\left(N_{S(M I N)}\right)$ values of $N_{S}$ are determined, from which the monthly range is obtained using the expression

$$
\text { Monthly Range }=N_{S(M A X)}-N_{S(M I N)}
$$

An assessment of the field strength variability (FSV) in a given location is investigated from the monthly ranges of $N_{s}$ using the expression [6].

$$
F S V=\left(N_{S(M A X)}-N_{S(M I N)}\right) \times 0.2 d B
$$


Near the surface (where refractivity gradient is approximately constant), the effective earth's radius model is adequate for lowelevation terrestrial radio propagation studies. Under such conditions, the radio horizon becomes an important parameter in determining the coverage area of a terrestrial radio link, depending on the transmitter height [30]. The radio horizon distance, $d_{R H}$ is theoretically the maximum distance an unobstructed radio signal will travel from the transmitter before grazing the surface, and for a receiver to be effective, it must be installed within that distance. The radio horizon distance depends on the transmitter height, $h_{T}$ and value of $N_{S}$ in the station, and may be obtained using the expression given by [31] as:

$$
d_{R H}=\sqrt{2 k r h_{T}}
$$

where $k$ is the effective earth radius factor and $r$ is the earth's radius $(6370 \mathrm{~km})$.

In this study, the skewness and kurtosis tests were also carried out. The skewness test $\left(\sigma_{k}\right)$ measures the asymmetry of the parameters data around their mean value; it is a measure of symmetry, or more precisely, the lack of symmetry [32]. It tells us about the direction of variation of the dataset [32]. If $\sigma_{k}=0$, the data have a Gaussian distribution (normal distribution), while $\sigma_{k}<$ 0indicates that the data are spread out more to the left of the mean value than to its right (negatively skewed), when $\sigma_{k}>0$ indicates that data are spread out more to the right than to its left (positively skewed) [33]. The Kurtosis test $\left(k_{u}\right)$ describes the shape of a random variable's probability distribution, that is it characterizes the relative peakedness or flatness of a distribution compared to the normal distribution [32]. It measures the degree of normality of each of the meteorological parameters under investigation [33]. For $k_{u}=0$ the data have normal distribution, for $k_{u}>0$ the data have positive kurtosis which implies peaked distribution, that is, leptokurtic distribution (that is, too tall), when $k_{u}<0$ the data have negative kurtosis which implies flat distribution, that is, platykurtic distribution (that is, too flat, or even concave if the value is large enough).

\section{RESULTS AND DISCUSSION}

\subsection{Radio refractivity and its variation with other meteorological parameters}

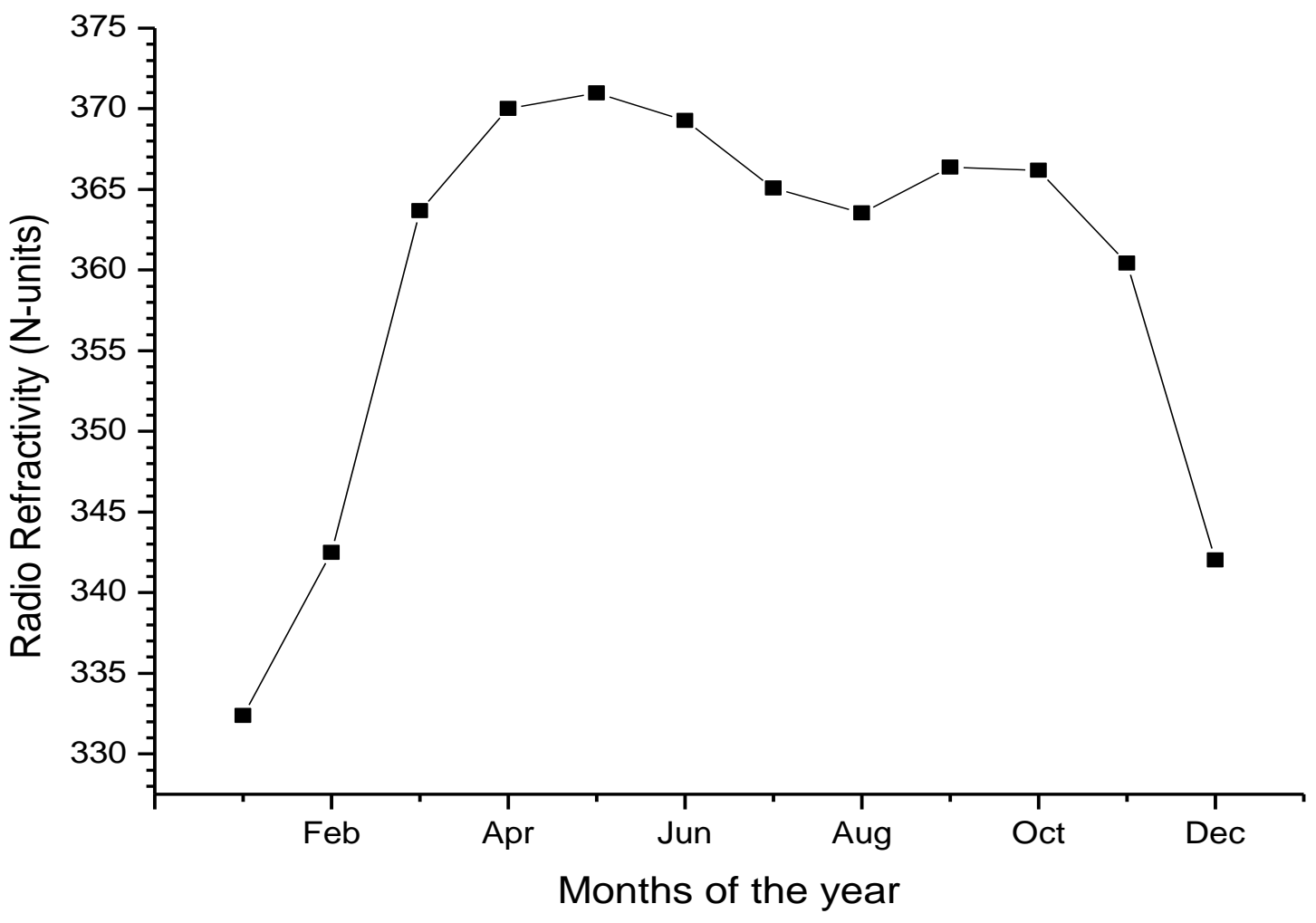

Figure 2. Seasonal radio refractivity variation over Osogbo, Nigeria

Figure 2 depicts the seasonal variation of radio refractivity for Osogbo during the period under investigation. The radio refractivity at Osogbo, Osun State, Nigeria showed gradual increase from a minimum value of $332.36 \mathrm{~N}$-units in the month of 
January until it gets to its peak value of $370.98 \mathrm{~N}$-units in the month of May and decreases gradually until it gets to $363.53 \mathrm{~N}$-units in August which suddenly increases until it reaches another maximum value of $366.38 \mathrm{~N}$-units in the month of September and drops to $342.03 \mathrm{~N}$-units in December. It is worthy of note from the figure that when the dry harmattan season sets in by November, there is a sharp and steady fall in the radio refractivity value until January when the lowest value was observed. The maximum average value of radio refractivity observed for Osogbo is $370.98 \mathrm{~N}$-units in the month of May and the minimum value of $332.36 \mathrm{~N}$-units in January during the rainy and dry seasons respectively. The pattern of variation can be attributed to rain pattern in Osogbo over the period under study. The results showed that high values of refractivity are observed during the rainy season with an average value of $367.35 \mathrm{~N}$-units and low values during the dry season with an average value of $348.19 \mathrm{~N}$-units. It is clear from the figure that the radio refractivity value dropped in the month of August; this is a time when the location experienced a short period of dryness, known as August break. This observation is similar to those carried out by different researchers e.g. Akpootu and Iliyasu [7] and Emmanuel et al. [17]. The study further revealed that high values of radio refractivity were observed during the rainy season (April - October) which are as a result of high air humidity (very close to $100 \%$ ) that gives rise to high water vapour pressure observed in most places of the country, during this time the city is under the influence of a large quantity of moisture-laden tropical maritime air emanating from continuous migration of inter-tropical discontinuity (ITD) with the sun. Generally, when the dry and dust -laden north-east winds become dominant in December, the dry harmattan season sets in, given rise to low refractivity values. The observed low values of radio refractivity during the dry season may be due to the low values of water vapour pressure and high temperature values during this period.

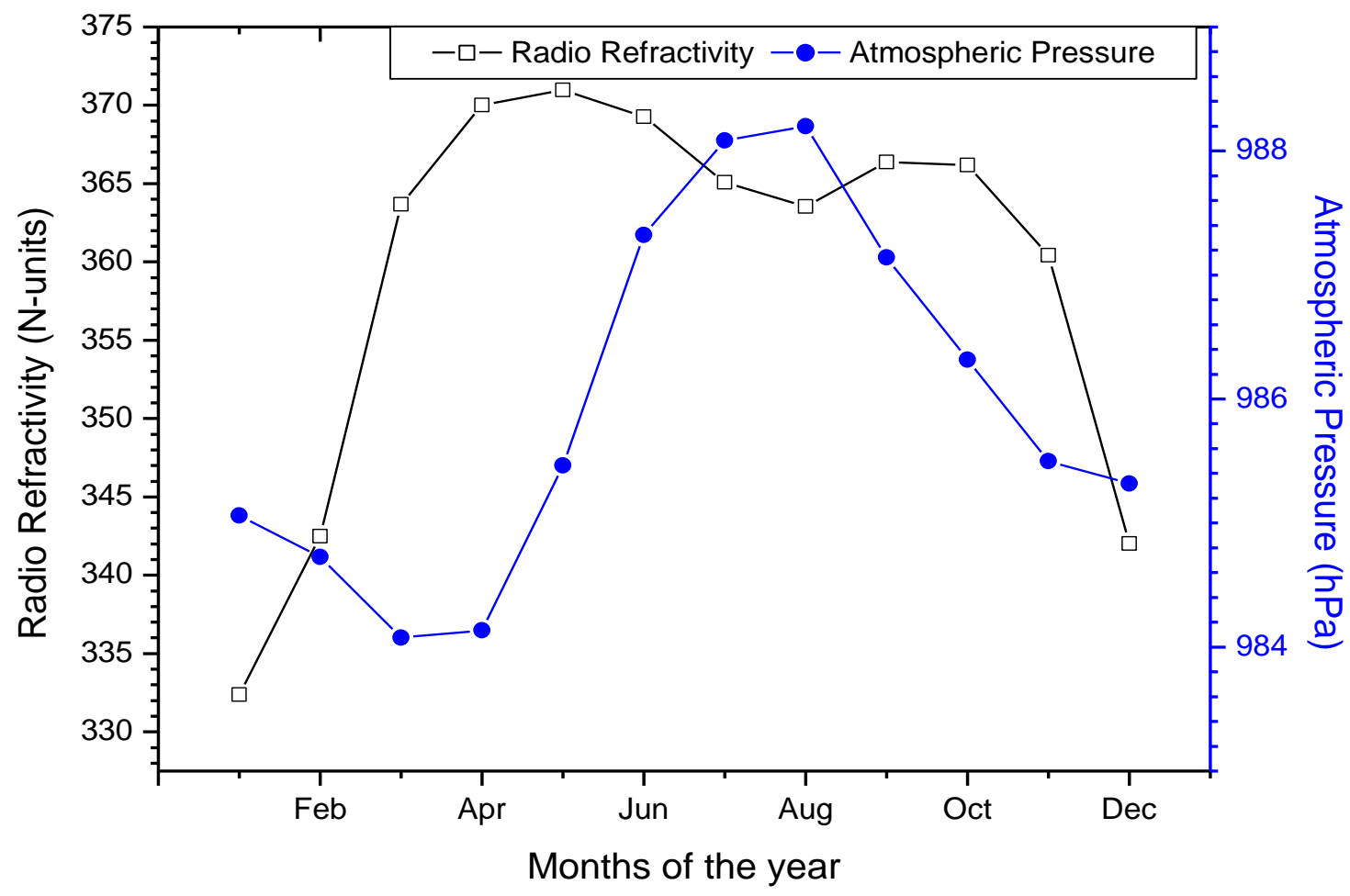

Figure 3. Seasonal variation of radio refractivity with atmospheric pressure over Osogbo, Nigeria

Figure 3 illustrates the Seasonal distinction of radio refractivity with atmospheric pressure for the study area. The atmospheric pressure decreases steadily in the month of January and attained its minimum value of $984.08 \mathrm{hPa}$ in March and slightly increases to April and then increases with a sharp rise in its values from April and attained its maximum value of $988.20 \mathrm{hPa}$ in August. It can be seen from the figure that as the refractivity decreases from May to August; the atmospheric pressure increases from March to August. The figure depicts that as the maximum value with dip upward was observed for atmospheric pressure a dip downward was also observed for the refractivity in the month of August; indicating that during August break Osogbo experiences the maximum value of atmospheric pressure; this observation is in line with the study carried out by Akpootu and Iliyasu [7] for Ikeja, Nigeria. The study revealed that as the atmospheric pressure decreases from August to December, the radio refractivity increases from August to September and suddenly drop in November when the dry harmattan season sets in and subsequently to December. It was found that an average value of $986.67 \mathrm{hPa}$ and $984.94 \mathrm{hPa}$ were observed during the rainy and dry seasons indicating high values of atmospheric pressure during the rainy season and less in the dry season, similarly, an average value of $367.35 \mathrm{~N}$-units 
and $348.19 \mathrm{~N}$-units were observed for the tropospheric radio refractivity during the rainy and dry seasons respectively. The dry term of radio refractivity is proportional to atmospheric pressure and therefore related to air density. The maximum and minimum average values of atmospheric pressure were observed to be $988.20 \mathrm{hPa}$ and $984.08 \mathrm{hPa}$ in the months of August and March during the rainy and dry seasons for the location under investigation.

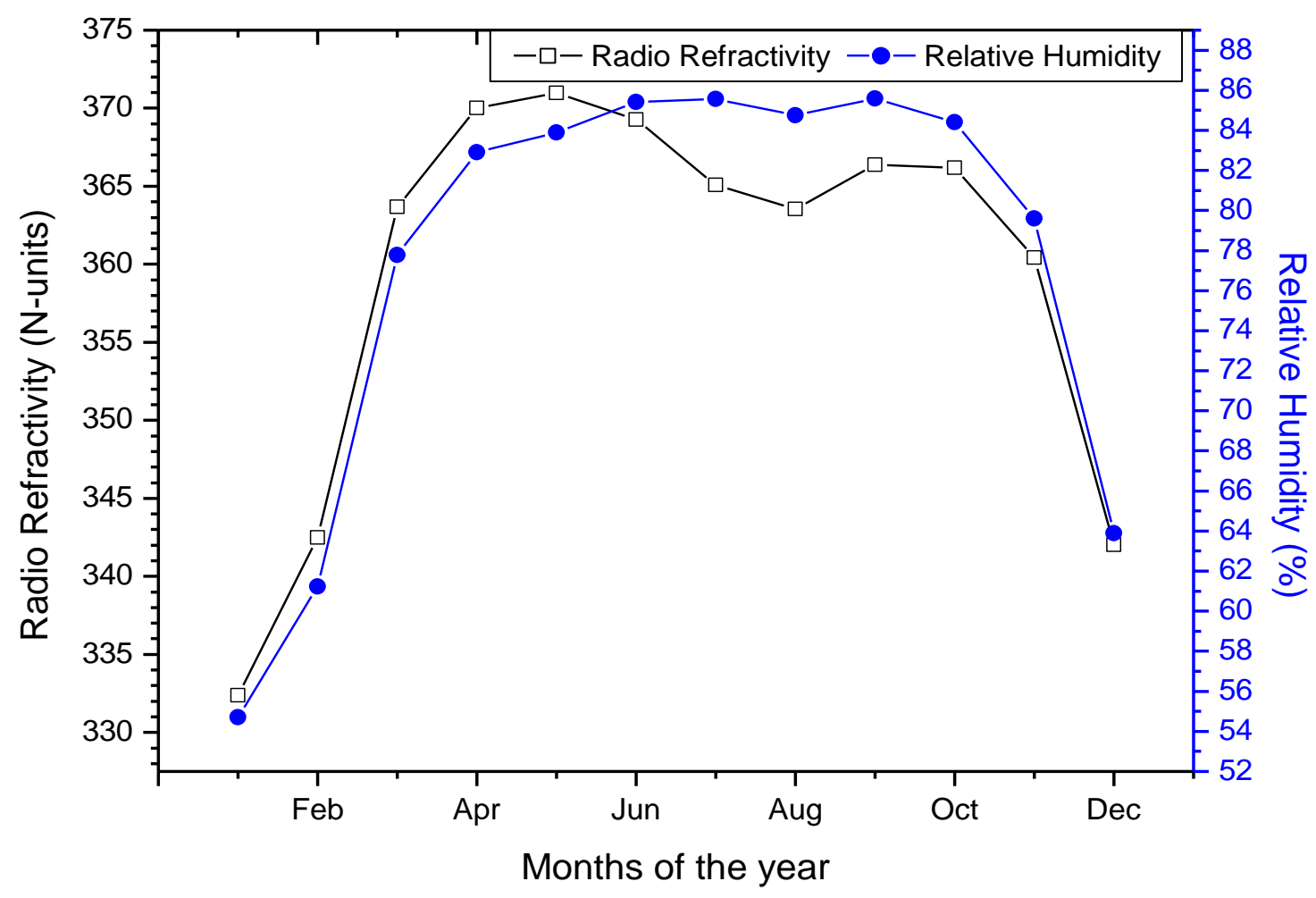

Figure 4. Seasonal variation of radio refractivity with relative humidity over Osogbo, Nigeria

Figure 4 illustrates the seasonal distinction between radio refractivity and relative humidity for Osogbo. The radio refractivity and relative humidity increases simultaneously from January to May; though, the relative humidity increases continuously until it reaches July. It was observed that the radio refractivity and relative humidity depicts a little dip downward in August; however, the dip downward for the radio refractivity is more evident as compared to the relative humidity and this observation is in line with the study reported by Akpootu and Iliyasu [7] and Emmanuel et al [17] for coastal zones. It was observed that the relative humidity increases with the radio refractivity from August to September and drop subsequently to December. There is a sharp fall in the values of the relative humidity and radio refractivity in December; this may be due to high solar irradiance in the month of December that reduced humid content in the atmosphere, thereby reducing the radio refractivity. The study revealed an average value of $84.65 \%$ and $67.44 \%$ during the rainy and dry seasons; indicating high values during the rainy season and low values in the dry. The maximum and minimum values of relative humidity were observed to be $85.59 \%$ and $54.70 \%$ in the month of September and January during the rainy and dry seasons respectively. The result of this study showed that the relative humidity is a reflection of the radio refractivity. 


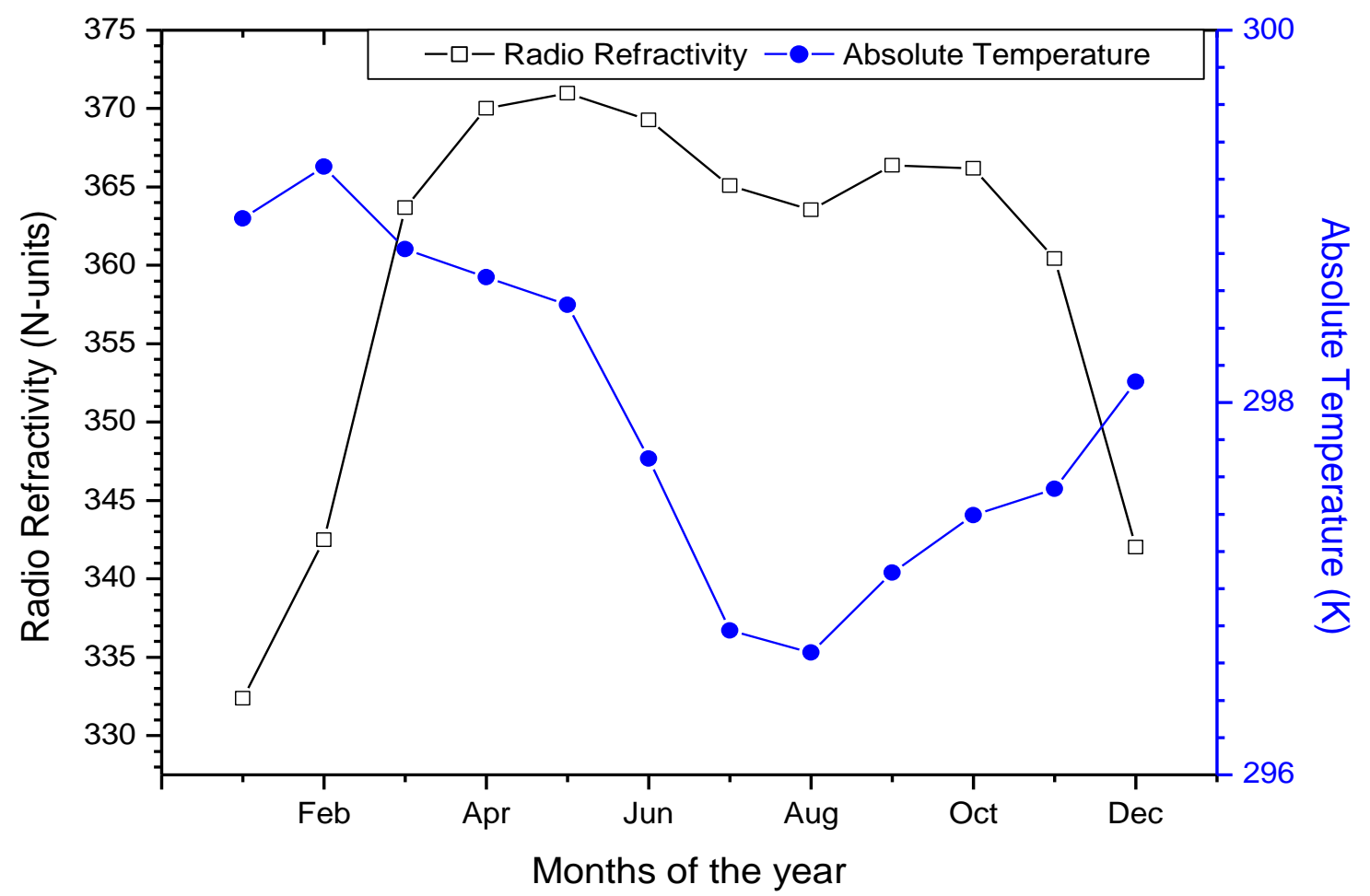

Figure 5. Seasonal variation of radio refractivity with temperature over Osogbo, Nigeria

Figure 5 illustrates the seasonal distinction of radio refractivity with temperature (Kelvin) for Osogbo. The temperature value increases from January and attained its maximum average value of $299.27 \mathrm{~K}$ in February and decreases subsequently until it attained its minimum value in August; in the same vein, the radio refractivity increases from its minimum value in the month of January and attained its maximum value in May. It was observed that in August both the temperature and radio refractivity exhibit a little dip downward. The temperature values increase steadily from August to December, while those of the radio refractivity increase from August to September and drop in December. The study showed that an average value of $298.55 \mathrm{~K}$ and $297.54 \mathrm{~K}$ are found during the dry season and rainy season; this is expected as high solar radiation and temperature values are in the dry season. The values of radio refractivity are observed to be high during the rainy season; this may be due to high moisture or humidity content in the atmosphere and low temperature. The maximum temperature was observed during the dry season in the month of February with an average value of $299.27 \mathrm{~K}$ while the minimum temperature was observed in August with an average value of $296.66 \mathrm{~K}$, this obviously showed that the observed lowest temperature values occurred when the sky is partly cloudy and partly clear for the location under study. The results of this study indicated that the temperature is an opposite reflection of the radio refractivity. 


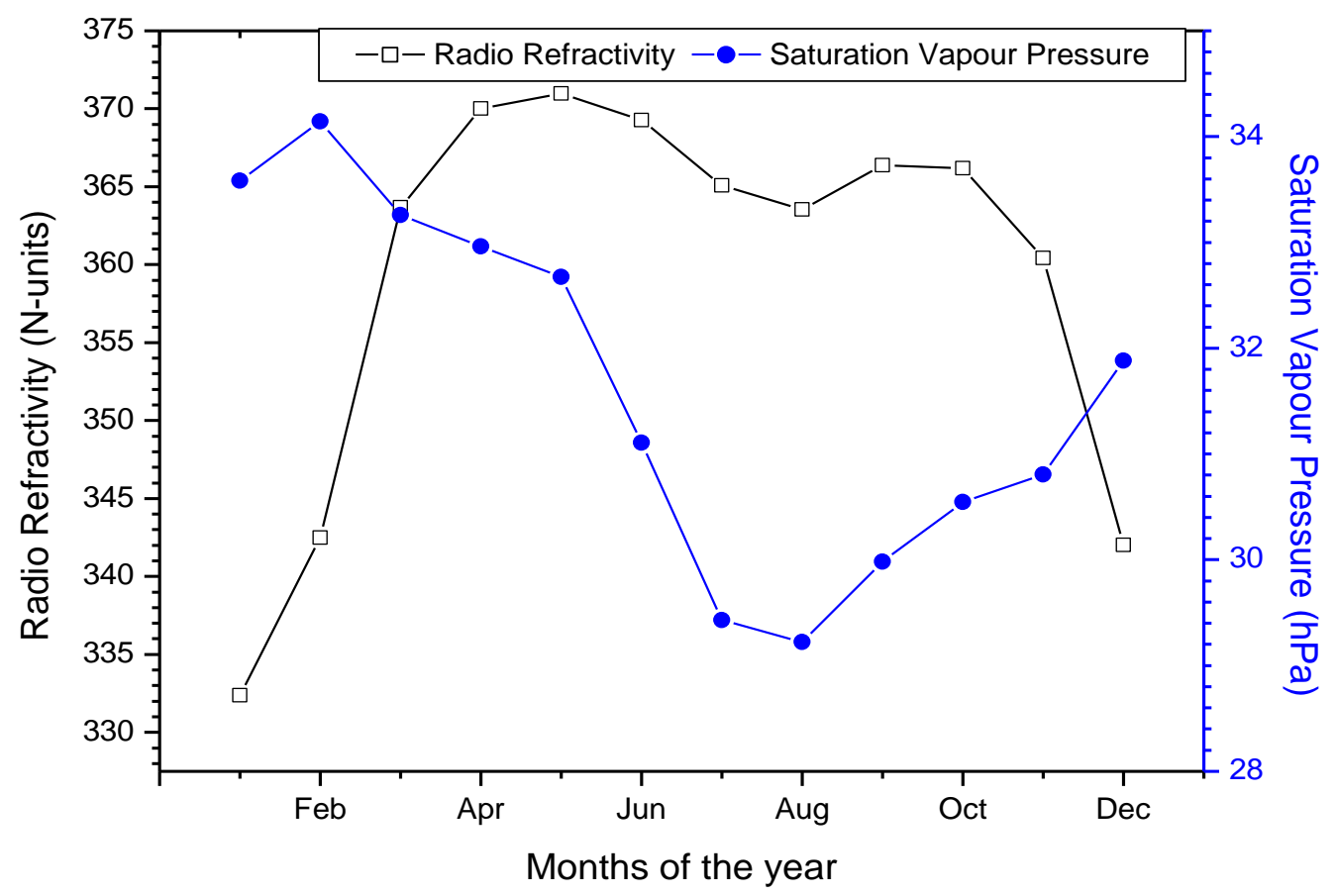

Figure 6. Seasonalvariations of radio refractivity with saturation vapour pressure over Osogbo, Nigeria

Figure 6 illustrates the seasonal distinction between the radio refractivity with saturation vapour pressure. The pattern of variation is similar to that of the seasonal variation between radio refractivity and temperature (Figure 5). This shows that the saturation vapour pressure is dependent on the temperature and it's a reflection of it. This observation is in line with the study carried out for Ikeja by Akpootu and Iliyasu [7].

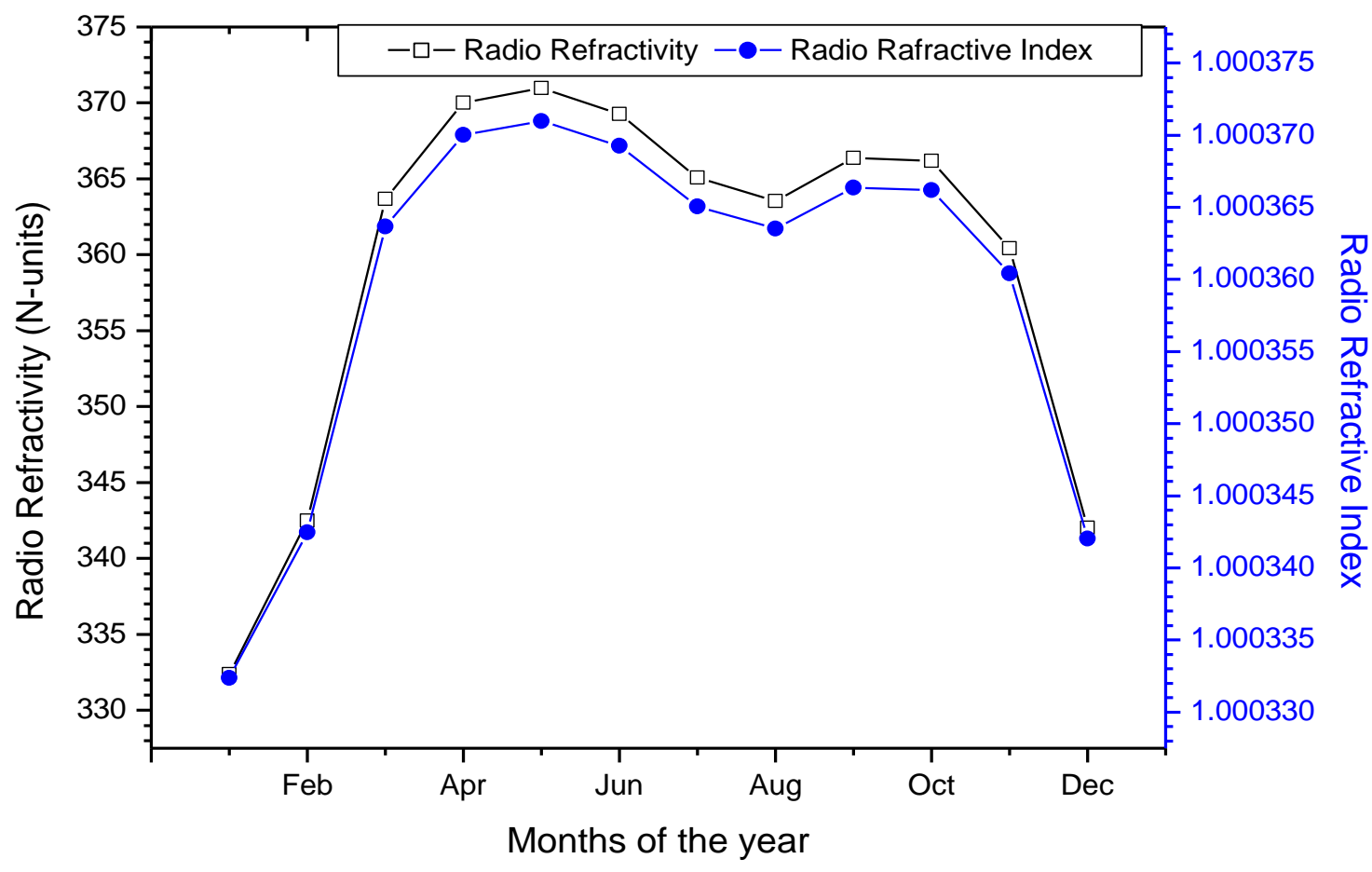

Figure 7. Seasonal variation of radio refractivity with refractive index over Osogbo, Nigeria 
Figure 7 illustrates the seasonal variation of radio refractivity with refractive index for Osogbo. The results revealed that the radio refractive index and radio refractivity values indicated seasonal variation with high values during the rainy season and low values during the dry season. The average values of radio refractive index during the rainy and dry seasons are 1.000367 and 1.000348 respectively. The average values of radio refractivity during the rainy and dry seasons are $367.35 \mathrm{~N}$-units and $348.19 \mathrm{~N}$-units. The maximum and minimum average values of radio refractive index are 1.000371 and 1.000332 in the months of May and January during the rainy and dry seasons respectively. The maximum and minimum average values of radio refractivity were observed to be $370.98 \mathrm{~N}$-units and 332.26 N-units in the months of May and January during the rainy and dry seasons respectively.

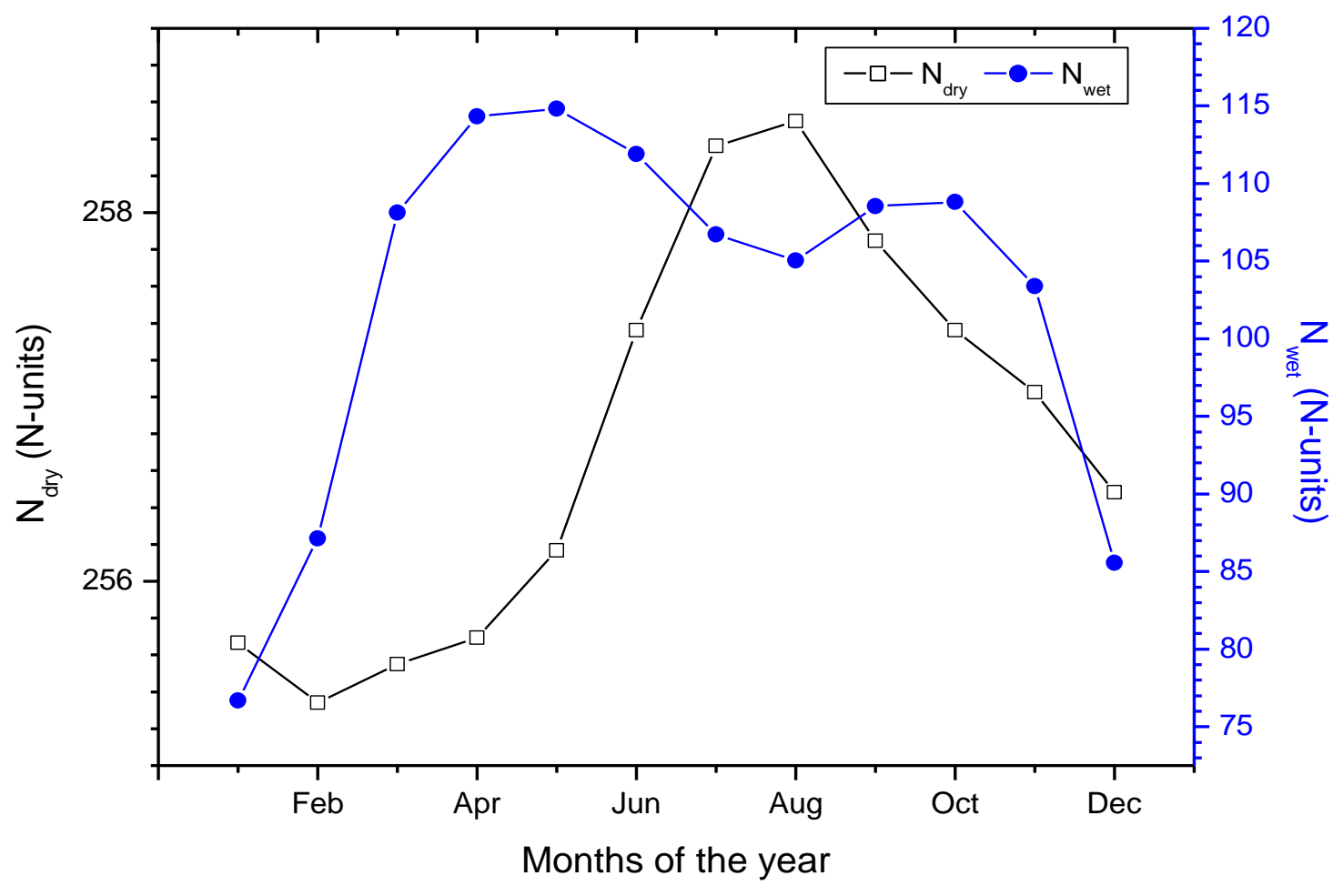

Figure 8. Seasonal variation of dry and wet terms radio refractivity over Osogbo, Nigeria

Figure 8 illustrates the seasonal variation of dry term radio refractivity $\left(\mathrm{N}_{\text {dry }}\right)$ and wet term radio refractivity $\left(\mathrm{N}_{\text {wet }}\right)$. The findings revealed that the dry term of radio refractivity contributes significantly to the total value of the radio refractivity for Osogbo. The pattern of variation demonstrated by the dry term is somewhat alike to that of atmospheric pressure, shown in Figure 3 . The major difference is that the minimum values of atmospheric pressure and dry term of the radio refractivity were observed in the months of March and February respectively. The similarity in the pattern of variation connotes that the dry term of radio refractivity is proportional to the atmospheric pressure and related to air density. Conversely, the wet term and the radio refractivity (Figure 2) exhibit similar variation. Therefore, we can conclusively say that the wet term of radio refractivity contributes to the major variation of the radio refractivity while the dry term is a major contributor to the total value. 


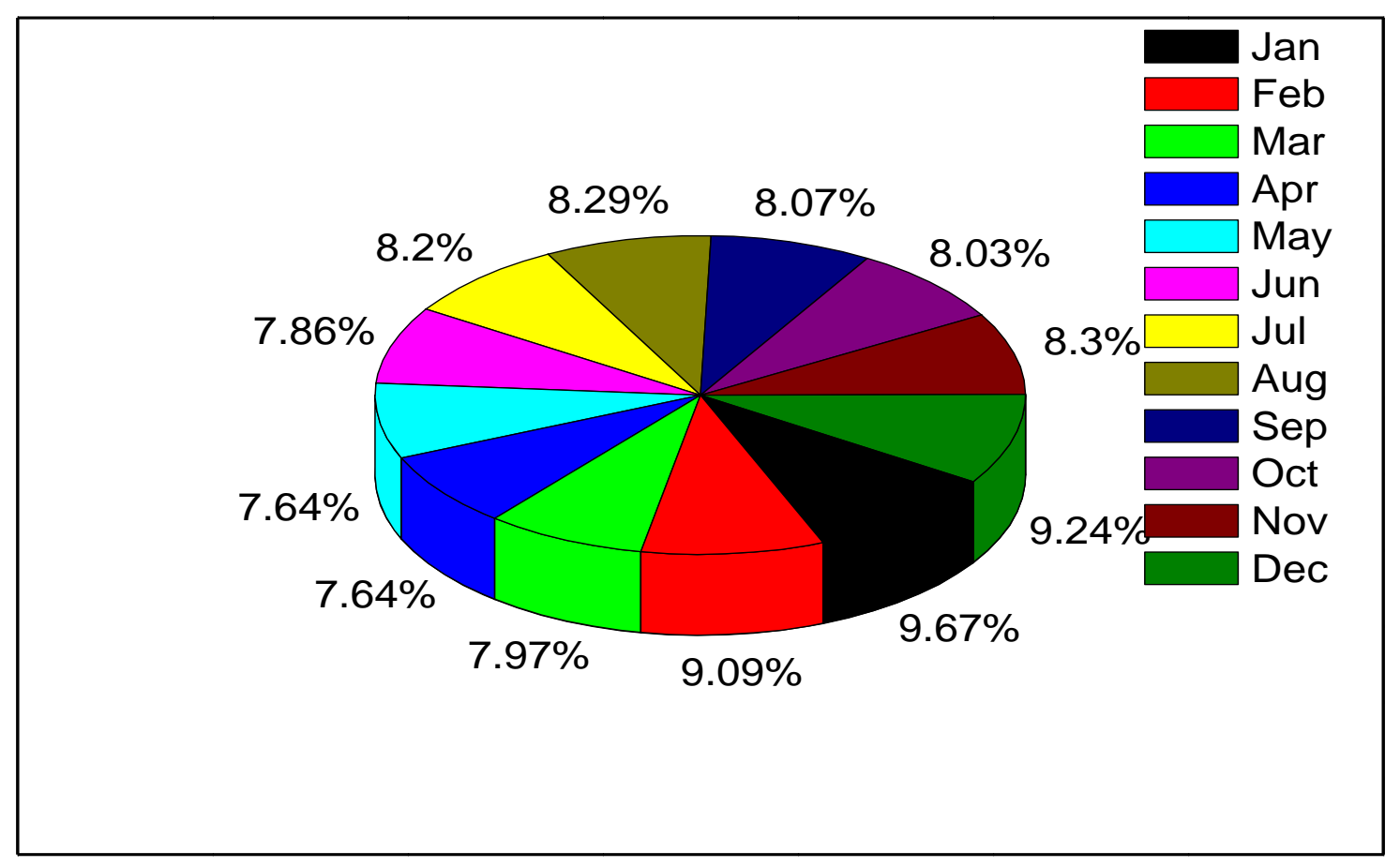

Figure 9. Seasonal variation of percentage difference between the dry and wet term radio refractivity over Osogbo, Nigeria

The pie chart in figure 9 explains the seasonal variation of percentage difference between the $\mathrm{N}_{\text {dry }}$ and $\mathrm{N}_{\text {wet }}\left(\mathrm{N}_{\text {dry }}-\mathrm{N}_{\text {wet }}\right)$. The result of this study showed that the minimum percentage differences occurred in the month of May (about $7.64 \%$ ) while the maximum value was in January (about $9.67 \%$ ). This are the months where the maximum and minimum values of radio refractivity occurred.

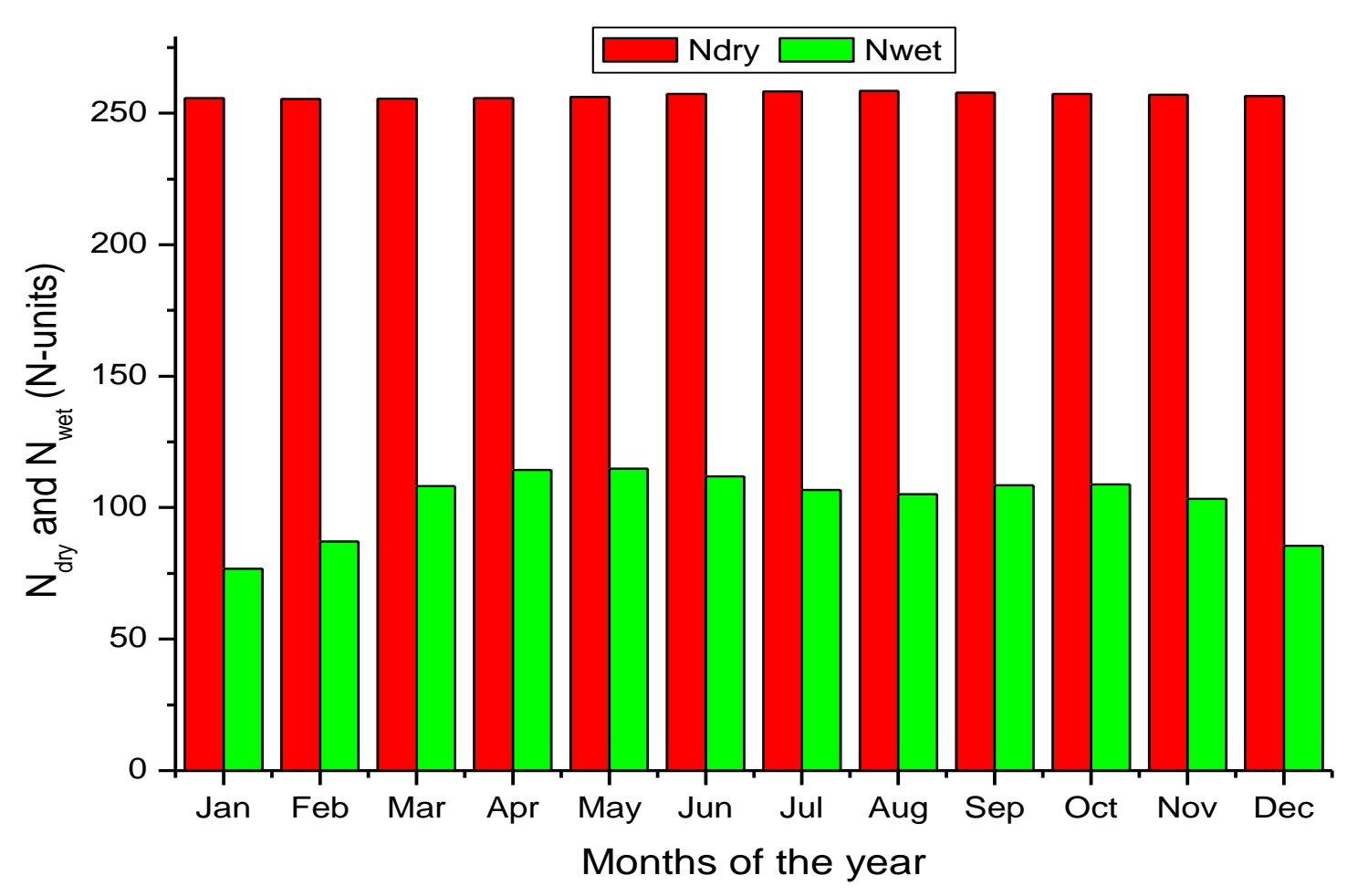

Figure 10. Seasonal variation of dry and wet term radio refractivity over Osogbo, Nigeria 
Figure 10 shows the monthly variation of dry and wet term radio refractivity. It was observed that the dry term radio refractivity are the major contributors to the total radio refractivity, the highest value of $\mathrm{N}_{\text {dry }}$ is recorded in the month of August as $258.50 \mathrm{~N}$ units and the lowest in the month of February as $255.34 \mathrm{~N}$-units. On the other hand, the highest value of $\mathrm{N}_{\text {wet }}$ is recorded in the month of May as $114.81 \mathrm{~N}$-units and the lowest in the month of January as $76.70 \mathrm{~N}$-units.

\subsection{Refractivity gradient and effective earth radius}

The refractivity gradient and $\mathrm{k}$ - factor obtained for Osogbo using equations (9) is $-42.69 \mathrm{~N}$-units $/ \mathrm{km}$. The implication of the result is that propagation in this geographic region is mostly super-refractive, which implies that the electromagnetic waves are bent downward towards the earth. The degree of bending is a function of the strength of the super-refractive condition. As the refractivity gradient continues to decrease, the wave path's curve will approach the radius of curvature of the earth. Super refraction occurs when the bending of the trajectory of propagating radio wave bends towards the ground surface is greater than its bending in case of normal positive refraction. Akpootu and Iliyasu [7] obtained super refractive propagation for Ikeja in the coastal region.

The effective earth radius, $\mathrm{k}$ - factor obtained for Osogbo using equation (10) is 1.37. The result indicated that propagation in this geographic region is mostly super-refractive. Super refraction results from such meteorological conditions as a rise in temperature with increasing height (temperature inversion), or a marked decrease in total moisture content in the air, either of which will cause a reduction in the dielectric constant gradient with height. Under these situations the K-factor increases resulting in an effective flattening of the equivalent earth's curvature. One of the conditions which may cause this type of abnormal refraction is the passage of warm air over a cool body of water and water evaporation can cause an increase in moisture content and a decrease in temperature near the surface, therefore producing a temperature inversion. However, it is not only the temperature inversion itself which causes the abnormal bending of the microwave beam. The large increase in water vapour content and hence, the dielectric constant near the surface further increases this effect. Akpootu and Iliyasu [7] obtained super refractive propagation for Ikeja in the coastal region.

\subsection{Field strength variability (FSV) and radio horizon distance}

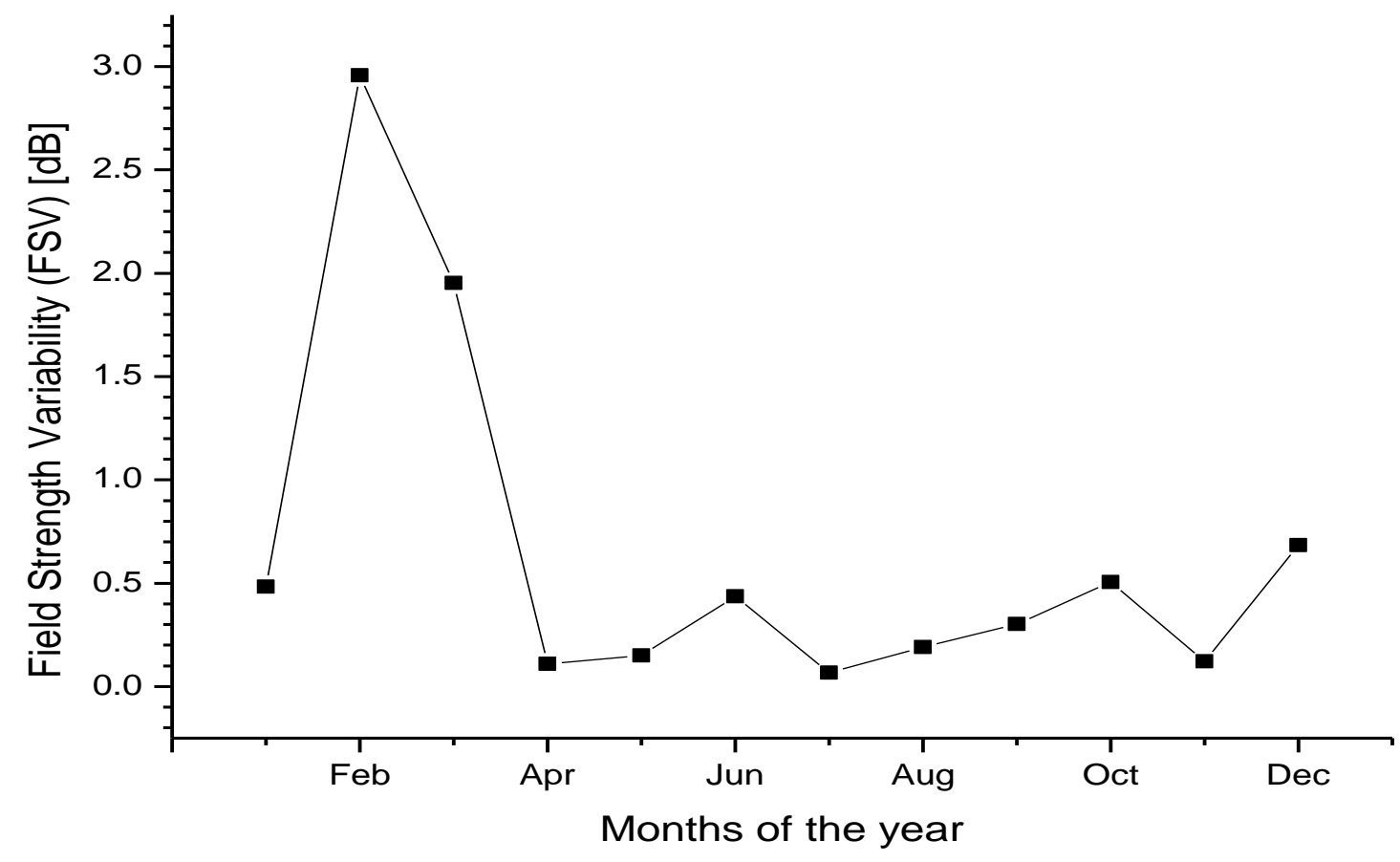

Figure 11. Monthly variation of field strength variability over Osogbo, Nigeria

The field strength variability (FSV) was obtained equation (11) and (12).Considering the twenty two years(July 1983 - June 2005) data, the FSV is $7.72 d B$ while using two years $(2003$ - 2004) data, the maximum and minimum FSV values of $2.98 d B$ and 
$0.07 d B$ were obtained in the months of February and July during the rainy and dry seasons respectively. The result of this study as seen from figure 11 revealed that the field strength values are high during the dry season and was found to be low and stable during the rainy season; this is in agreement with the study reported by Adediji et al [6] for Akure, Nigeria. The implication of the FSV values in this study area is that the output of a receiving antenna in Osogbo may generally be subjected to changes not less than $0.07 d B$ in a year, but should not be greater than $7.72 d B$.

The radio horizon distance was obtained using equation (13). The equation obtained for computing the radio horizon distance is given by the expression

$$
d_{R H}=132.28 \sqrt{h_{T}}
$$

Equation (14) can be used for computing the radio horizon distance for Osogbo provided the transmitter height, $h_{T}$ is known.

\subsection{Percentage contribution and descriptive statistical analysis}

Table 1. Monthly variation of the percentage contribution of $\mathrm{N}_{\mathrm{dry}}$ and $\mathrm{N}_{\mathrm{wet}}$ for Osogbo, Nigeria

\begin{tabular}{cccc}
\hline Month & Ndry-Nwet & \%CNdry & \%CNwet \\
\hline Jan & 178.97 & 5.93 & 1.78 \\
Feb & 168.20 & 5.92 & 2.02 \\
Mar & 147.42 & 5.93 & 2.51 \\
Apr & 141.37 & 5.93 & 2.65 \\
May & 141.36 & 5.94 & 2.66 \\
Jun & 145.45 & 5.97 & 2.60 \\
Jul & 151.65 & 5.99 & 2.47 \\
Aug & 153.46 & 5.99 & 2.44 \\
Sep & 149.32 & 5.98 & 2.52 \\
Oct & 148.54 & 5.97 & 2.52 \\
Nov & 153.64 & 5.96 & 2.40 \\
Dec & 170.93 & 5.95 & 1.98 \\
Total & & $\mathbf{7 1 . 4 5}$ & $\mathbf{2 8 . 5 5}$ \\
\hline
\end{tabular}

Table 1 shows the monthly variation of the percentage contribution of both the dry term and wet term radio refractivity to the total radio refractivity. It was observed that the dry term radio refractivity is a major contributor to the total radio refractivity with 71.45 $\%$ while the wet term radio refractivity has $28.55 \%$ for Osogbo, Osun State, South Western, Nigeria during the period under investigation. It was also observed that the monthly maximum contribution of the dry term is in the months of July and August with $5.99 \%$ and minimum in the month of February with $5.92 \%$, similarly, the monthly maximum contribution for the wet term is in the month of May with $2.66 \%$ and minimum in the month of January with $1.78 \%$.

Table 2. Radio refractivity and other parameters descriptive statistical analysis for Osogbo, Nigeria

\begin{tabular}{lrrrrrr}
\hline & Range & Minimum & Maximum & Sum & Skewness & \multicolumn{1}{c}{ Kurtosis } \\
& Statistic & Statistic & Statistic & \multicolumn{1}{c}{ Statistic } & Statistic & \multicolumn{1}{c}{ Statistic } \\
\hline $\mathrm{N}$ & 38.6137 & 332.3642 & 370.9779 & 4312.4049 & -1.2730 & 0.2550 \\
Atmospheric & 4.1224 & 984.0770 & 988.1994 & 11831.3410 & 0.3690 & -1.2020 \\
$\mathrm{P}$ & & & & & & \\
$\mathrm{RH}$ & 30.8956 & 54.6957 & 85.5913 & 929.7314 & -1.2930 & 0.1560 \\
Absolute & 2.6107 & 296.6562 & 299.2670 & 3575.5330 & -0.0530 & -1.4360 \\
$\begin{array}{l}\text { Temp } \\
\mathrm{n}\end{array}$ & & & & & & \\
\hline
\end{tabular}


The results shown in Table 2 showed that the radio refractivity, relative humidity (RH), absolute temperature and radio refractive index data spread out more to the left of their mean value (negatively skewed), while the atmospheric pressure data spread out more to the right of its mean value (positively skewed). It is clear from Table 2 that the radio refractivity, relative humidity and radio refractive index data have positive kurtosis which indicates a relatively peaked distribution and possibility of a leptokurtic distribution. The atmospheric pressure and absolute temperature data have negative kurtosis which indicates a relatively flat distribution and possibility of platykurtic distribution.

\section{CONCLUSION}

This study addresses the issue of estimating tropospheric radio refractivity under changing atmospheric conditions for Osogbo (Latitude $7.47^{0} \mathrm{~N}$, Longitude $4.29^{0} \mathrm{E}$ and altitude $302.0 \mathrm{~m}$ above sea level), Osun state located in the south western, Nigeria. The procedure recommended by the International Telecommunication Union (ITU) was implemented in the evaluation of tropospheric radio refractivity for the location during the period of twenty two years (July 1983 - June 2005) using monthly average daily atmospheric pressure, relative humidity and temperature data obtained from the National Aeronautics and Space Administration (NASA). The results revealed that an average value of $367.35 \mathrm{~N}$-units and $348.19 \mathrm{~N}$-units were observed during the rainy and dry seasons indicating that radio refractivity are more during the rainy season than in the dry season for Osogbo. The maximum and minimum radio refractivity values of $370.98 \mathrm{~N}$-units and $332.36 \mathrm{~N}$-units were observed in the months of May and January during the rainy and dry seasons respectively. The dry term contributes $71.45 \%$ to the total value of the radio refractivity while the wet term contributes $28.55 \%$ indicating that the dry term is a major contributor to the total value of the radio refractivity while the wet term contributes to the major variation. The average refractivity gradient and $\mathrm{k}-$ factor of $-42.69 \mathrm{~N}$-units/km and 1.37 were obtained for Osogbo signifying that propagation in this geographic zone is mostly super-refractive. The monthly variation of FSV revealed that high values were recorded during the dry season and low and stable values during the rainy season.

The annual maximum mean value of FSV is $7.72 \mathrm{~dB}$ and minimum monthly mean value of $0.07 \mathrm{~dB}$ was obtained for the study area signifying that the output of a receiving antenna in Osogbo may generally be subjected to changes not less than $0.07 \mathrm{~dB}$ in a year and not greater than $7.72 \mathrm{~dB}$. The expression given in equation (14) has been determined for computing the radio horizon distance for Osogbo. The descriptive statistical analysis shows that the radio refractivity, relative humidity, absolute temperature and radio refractive index data spread out more to the left of their mean value (negatively skewed), while the atmospheric pressure data spread out more to the right of their mean value (positively skewed). The radio refractivity, relative humidity and radio refractive index data have positive kurtosis which indicates a relatively peaked distribution and possibility of a leptokurtic distribution. The atmospheric pressure and absolute temperature data have negative kurtosis which indicates a relatively flat distribution and possibility of platykurtic distribution. The results obtained from this investigation are highly significant for optimal planning and design of microwave communication links for Osogbo, Osun State and regions with similar climatic information.

\section{ACKNOWLEDGEMENT}

The authors wish to appreciate the management and staff of the National Aeronautics and Space Administration (NASA) atmospheric science data centre under Surface meteorology and Solar Energy for making all the relevant data used in this present study available online. The contribution and suggestions of the anonymous reviewers is well appreciated.

\section{REFERENCES}

[1] Adediji, A. T., Adebusola, S. O and Ojo, J. S (2017). Variability of Microwave Radio Refractivity and Field Strength over Some Selected Locations in Nigeria.Physical Science International Journal. 14(3): 1-11.

[2] Adediji, A. T and Ajewole, M. O (2008). Vertical profile of radio refractivity gradient in Akure South-West Nigeria. Progress in Electromagnetics Research C. 4:157-168.

[3] Freeman, R. L (2007). Radio system design for telecommunications (3rd Ed.).New York: Wiley-Inter Science.

[4] Harada, H and Fujise, M (2003). Research on mobile communications in microwave and millimeter-wave frequency ranges at CRL.Wireless Personal Communications, 26, 117-133.

[5] Johny, C. J., Sarkar, S. K and Punyasesudu, D (2009). Atmospheric phenomena deduced from radiosonde and GPS occultation measurements for various application related studies. Journal of Earth SystemScience, 118, 49-59. 
[6] Adediji, A. T., Ismail, M and Mandeep, J. S (2014). Performance analysis of microwave radio refractivity on radio field strength and radio horizon distance over Akure, Nigeria, Wireless Personal Communications. 79:1893-1909 DOI 10.1007/s11277-014-1963-0.

[7] Akpootu, D. O and Iliyasu, M. I (2017). Estimation of Tropospheric Radio Refractivity and Its Variation with Meteorological Parameters over Ikeja, Nigeria. Journal of Geography, Environment and Earth Science International 10(1): 1-12.

[8] Hall, M. P. M (1979). Effects of the troposphere on radio communication.Institute of Electrical Engineers.

[9] Adediji, A. T (2017). Reduced-to-Sea-level Value of Microwave Radio Refractivity over three Stations in Nigeria. Nigeria Journal of Pure and Applied Physics, Vol. 7, No. 1, pp 19-25.

[10] John, S. S (2005). Introduction to RF propagation. John Wiley and Sons, Inc. Hoboken, New Jersey.

[11] Agunlejika, O and Raji, T. I (2010a). Empirical evaluation of wet-term of refractivity in Nigeria.International Journal of Engineering and Applied Sciences (IJEAS). 2(2): 63-68.

[12] Priestley, J. T and Hill, R. J (1985). Measuring high frequency refractive index in the surface layer. J. Atmos. Oceanic Technol. 2(2):233-251.

[13] Adeyemi, B (2006). Surface water vapor density and tropospheric radio refractivity linkage over three stations in Nigeria. Journal of Atmospheric and Solar- Terrestrial Physics. 68:1105-1115.

[14] Agbo, G. A (2011). Tropospheric refractivity dependence on atmospheric weather conditions in Jos - Nigeria. Journal of Basic Physical Research. 2(2):2-6.

[15] Ayantunji, B. G., Okeke, P. N and Urama, J. O (2011). Diurnal and seasonal variation of surface refractivity over Nigeria.Progress in Electromagnetics Research. 30:201-222.

[16] Žilinskas, M., Tamošiunas, S., Tamošiūnaitè, M and Tamošiūnienė, M (2011). Yearly, Seasonal and daily variations of radio refractivity.Physical Aspects of Microwave and Radar Applications. 119:533-536.

[17] Emmanuel, I., Adeyemi, B and Adedayo, K. D (2013). Regional variation of columnar refractivity with meteorological variables from climate monitoring satellite application facility (CM SAF) data over Nigeria.International Journal of Physical Sciences. 8(17):825-834.

[18] Luhunga, P. M., Mutayoba, E., Masoud, H., Chang'a, L and Prodanov, A. D (2014). Analysis of tropospheric radio refractivity over Julius Nyerere International Airport, Dar es Salaam. 1(2):21-31.

[19] Ajileye, O. O (2015). Long-term average of effective earth radius factor over West Africa using satellite meteorological dataset.International Journal of Electronics Communication and Computer Engineering. 6(2):175-179.

[20] Ajewole, M. O., Oyedum, O. D., Adediji, A. T., Moses, A. S and Eiche, J. O (2013). Spatial Variability of VHF/UHF Electric Field Strength in Niger State, Nigeria.International Journal of Digital Information and Wireless Communications (IJDIWC), The Society of Digital Information and Wireless Communications. 3(3): 231-239.

[21] Adegoke, C. W and Sojobi, A. O (2015). Climate Change Impact on Infrastructure in Osogbo Metropolis, South-West Nigeria.Journal of Emerging Trends in Engineering and Applied Sciences (JETEAS) 6(3): 156- 165.

[22] National Bureau of Statistics (2010). Annual Abstract of Statistics NBS, Federal Republic of Nigeria.

[23] International Telecommunication Union recommendation, ITU-R (2003). The radio refractive index: Its formula and refractivity data. $453-459$.

[24] Agunlejika, O and Raji, T. I (2010b).Validation of ITU-R model for atmospheric refractivity profile in a tropical region.International Journal of Engineering and Applied Sciences (IJEAS).2 (4): 72-82.

[25] Hall, M. P. M (1989). Effect of the troposphere on radio communication, IEEE electromagnetic wave series, Peter Peregrinus Ltd, United Kingdom.105-116.

[26] Afullo, T. J., Motsoela, T and Molotsi, D. F (1999). Refractivity Gradient and k-factor in Botswana.Radio Africa.107-110. 
[27] Maitham, A and Asrar, V. H. S (2003). Signal strength measurement at VHF in the eastern region of Saudi Arabia. Arabian Journal for Science and Engineering. 28 (2C): 3-18.

[28] CCIR Report (1959) No 147, Los Angeles, 1959.

[29] Owolabi, I. E and Williams, V. A (1970). Surface radio refractivity patterns in Nigeria and the Southern Cameroon. Journal of West Africa Science Association, 1, 3-17.

[30] Oyedum, O. D (2009). Seasonal variability of radio field strength and horizon over Northern and Southern Nigeria.Nigeria Journal of Pure and Applied Physics, 5, 97-104.

[31] Bean, B. R and Dutton, E. J (1968). Radio meteorology. New York: Dover Publication Co.

[32] Akpootu, D. O., Iliyasu, M. I.,Mustapha, W., Aruna, S and Yusuf, S. O (2017). The Influence of Meteorological Parameters on Atmospheric Visibility over Ikeja, Nigeria.Archives of Current Research International.,9(3): 1-12.

[33] Hejase, H. A. N and Assi, A. H (2011). Time-Series Regression Model for Prediction of Monthly and Daily Average Global Solar Radiation in Al Ain City-UAE. Proceedings of the Global Conference on Global Warming held on 11 - 14 July, 2011 , Lisbon, Portugal. Pp $1-11$. 